\title{
Focus Inuit research agenda on best outcomes
}

\author{
Chris Cunningham PhD BSc
}

Previously published at www.cmaj.ca

$\infty \quad$ See related research articles by Luo and colleagues, page 235, and by Egeland and colleagues, page 243

$\mathrm{T}$

wo papers on the health of Inuit populations demonstrate the challenge of research on indigenous populations. ${ }^{1,2}$ That challenge is to move past description to understanding - on scientific and indigenous terms the factors, environments and programs that yield the best outcomes for Inuit.

Luo and colleagues report on the differential and poorer birth outcomes for the largely rural Inuit population when compared with other populations in Canada. Higher rates of premature birth, stillbirth and infant mortality have persisted over time (from 1990 to 2000) in Inuit-inhabited areas of Canada, ${ }^{1}$ but these are likely to be underestimates for Inuit women and children because the analyses are based on geographic rather than ethnic stratification.

The article by Egeland and associates on food insecurity (i.e., inadequate quantity and quality of food supply) among Inuit preschoolers paints a picture of poorer outcomes for Inuit households and preschoolers when compared with other populations. ${ }^{2}$ The authors detail the prevalence of food insecurity and suggest that support systems be strengthened for Inuit families with young children.

Both articles provide evidence of unsurprising and familiar differences between Inuit and nonindigenous populations, but of greater interest is the approach used for the research. Each paper attempts to quantify the differences, in rigorous research terms, and suggests explanatory associations with factors characteristic of Inuit people. Yet each paper falls short of identifying the factors associated with best outcomes for Inuit populations or even those factors that might reliably be modified to produce best outcomes.

This phenomenon is not limited to Canada. Similar research literature on indigenous populations has appeared in the United States, Australia and New Zealand. Most such articles have a range of shortcomings. First, the use of imprecise definitions of indigenous populations - for example, statusdefined, genetically defined, self-defined, geographically defined or ancestry-defined populations - makes interpretation difficult. ${ }^{3}$ None of these definitions is wholly satisfactory, and each offers biases. They are also unreliable over time and between research projects, making comparisons difficult, if not misleading.

Second, many of the identifiable factors found for the Inuit populations being studied are not modifiable. For example, the youthful profile of indigenous populations is likely to

\section{Key points}

- Research on Inuit (indigenous) populations should focus on best outcomes and the circumstances by which they are delivered.

- Modifiable factors and responses by the health system should be the focus of research.

- Partnerships with nonindigenous peers can be fruitful, yet the agenda should be determined by indigenous people.

remain for some decades. For mothers and parents, this profile is often identified incorrectly as causal or associative and modifiable - teenage pregnancy is identified universally as problematic. However, this is not necessarily true among Inuit, Maori and Aboriginal populations, for whom social patterns of parenting across generations are such that negative outcomes are frequently avoided. ${ }^{4-6}$ The challenge for antenatal care providers and clinicians is their ability to respond to the many needs of young parents, particularly when those needs are different from those of older parents.

Third, such research is based on a deficit model, one that identifies poorer outcomes with poorer inputs characteristic of the population, lifestyle or environment in which Inuit and other indigenous peoples live. It misses opportunities to improve the responsiveness of health systems to the existing profile of indigenous populations.

Fourth, an analysis of the research findings for indigenous populations can point to parallel explanations and lead to the development of applications and interventions that are more responsive to indigenous needs and expectations.

Research on indigenous populations is increasing, and international networks are addressing related research agendas, methods and ethics, and the application of knowledge within frameworks that represent indigenous world views. ${ }^{7}$ Such efforts seek to change the balance of research on indigenous people to research with and by indigenous people. Partnerships with nonindigenous peers can be very fruitful. Frameworks that characterize these research approaches exist. ${ }^{8}$ Further, there is increasing literature on indigenous research and ana-

Chris Cunningham is with the Research Centre for Maori Health \& Development, Massey University, Wellington, New Zealand.

CMAJ 2010. DOI:10.1503/cmaj.092217

All editorial matter in CMAJ represents the opinions of the authors and not necessarily those of the Canadian Medical Association. 
lytical methods ${ }^{9,10}$ as well as much interest in researching at the interface of indigenous and scientific knowledge. ${ }^{11,12}$

Inuit Tapiriit Kanatami, the national organization representing Canadian Inuit, has spearheaded "2010 Year of the Inuit." This educational campaign aims to celebrate Inuit accomplishments and achievements and to increase awareness among the general Canadian population about issues facing Inuit. The initiative also seeks to encourage researchers to use scientifically credible research methods that consider the priorities of an indigenous population - a step that will lead to real gains in health for Canada's indigenous populations.

As researchers and health professionals, we should orient our activities in ways that address an indigenous agenda and recognize indigenous ways of understanding and applying the knowledge gained within our scientific and clinical paradigms.

Competing interests: None declared.

\section{REFERENCES}

1. Luo Z-C, Senecal S, Simonet F, et al. Birth outcomes in the Inuit-inhabited areas of Canada. CMAJ 2010 Jan. 25. [Epub ahead of print].
2. Egeland GM, Pacey A, Cao Z, et al. Food insecurity among Inuit preschoolers: Nanavut Inuit Child Health Survey, 2007-2008. CMAJ 2010 Jan. 25. [Epub ahead of print].

3. Bhopal R. Race and ethnicity: responsible use from epidemiological and public health perspectives. J Law Med Ethics 2006;34:500-7, 479.

4. Lewis LN, Hickey M, Doherty DA, et al. How do pregnancy outcomes differ in teenage mothers? A Western Australian study. Med J Aust 2009;190:537-41.

5. Butt L, Munro J. Rebel girls? Unplanned pregnancy and colonialism in highlands Papua, Indonesia. Cult Health Sex 2007:9:585-98.

6. Arabena K. Preachers, policies and power: the reproductive health of adolescent Aboriginal and Torres Strait Islander peoples in Australia. Health Promot J Austr 2006; 17:85-90.

7. Denzin NK, Lincoln YS, Smith LT. Handbook of critical and indigenous methodologies. Thousand Oaks (CA): Sage; 2008.

8. Cunningham C. A framework for addressing Maori knowledge in research, science and technology. Pac Health Dialog 2000;7:62-9.

9. Kerr S, Penney L, Moewaka Barnes H, et al. Kaupapa Maori action research to improve heart disease services in Aotearoa, New Zealand. Ethn Health 2009;Dec 16:1-17.

10. Barnes HM. Kaupapa Maori: explaining the ordinary. Pac Health Dialog 2000;7:13-6

11. Durie M. Understanding health and illness: research at the interface between science and indigenous knowledge. Int J Epidemiol 2004;33:1138-43.

12. Mercer J, Kelman I, Taranis L, et al. Framework for integrating indigenous and scientific knowledge for disaster risk reduction. Disasters 2010;34:214-39.

Correspondence to: Dr. Chris Cunningham, Research Centre for Maori Health \& Development, Massey University, PO Box 756, Wellington, New Zealand; C.W.Cunningham@massey.ac.nz

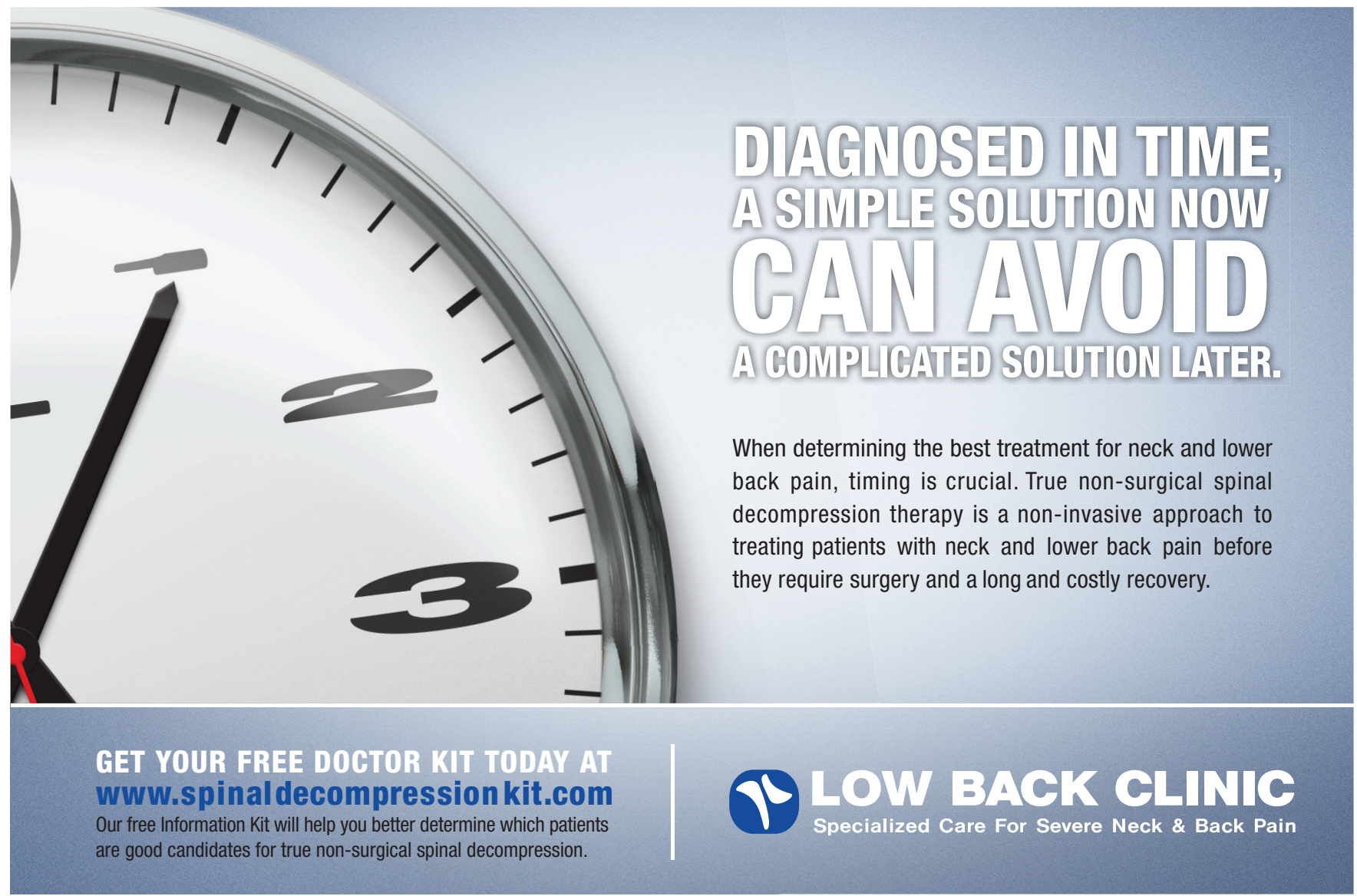

